This item was submitted to Loughborough's Research Repository by the author.

Items in Figshare are protected by copyright, with all rights reserved, unless otherwise indicated.

\title{
From racial exclusions to new inclusions: black and minority ethnic participation in football clubs in the East Midlands of England
}

\section{PLEASE CITE THE PUBLISHED VERSION}

http://dx.doi.org/10.1177/1012690210371562

\section{PUBLISHER}

SAGE Publications Ltd

VERSION

AM (Accepted Manuscript)

\section{PUBLISHER STATEMENT}

This work is made available according to the conditions of the Creative Commons Attribution-NonCommercialNoDerivatives 4.0 International (CC BY-NC-ND 4.0) licence. Full details of this licence are available at: https://creativecommons.org/licenses/by-nc-nd/4.0/

\section{LICENCE}

CC BY-NC-ND 4.0

\section{REPOSITORY RECORD}

Bradbury, Steven. 2019. "From Racial Exclusions to New Inclusions: Black and Minority Ethnic Participation in Football Clubs in the East Midlands of England". figshare. https://hdl.handle.net/2134/24541. 
From racial exclusions to new inclusions: Black and minority ethnic participation in football clubs in the East Midlands of England

Steven Bradbury

Loughborough University, UK

\begin{abstract}
This article reports on survey and interview data from a two-phase study examining the shape and scope of Black and Minority Ethnic (BME) participation in amateur football clubs in Leicestershire in the East Midlands of England. Survey results identified strongly differentiated patterns of participation and a concentration of BME (male) players, coaches and management committee members at a small number of clubs in the city of Leicester. Interview data contextualized the socio-historical development and ongoing reality of these BME clubs as a consequence of - and as active resistance to - racisms and exclusions within pre-existing and homogeneously White local football networks. BME clubs also had distinct social, cultural and religious attachments and had historically operated as symbolic and practical sites of community mobilization and cultural identity production for specific BME communities. Survey and interview data indicated that BME clubs and newer 'multiethnic' clubs increasingly featured a strong focus on the provision of valuable participation opportunities to younger players from a range of culturally and religiously diverse backgrounds and from communities experiencing disproportionate levels of social and economic deprivation. The article concludes by examining the role of BME clubs and newer 'multi-ethnic' clubs as facilitators of new inclusions and positive multi-cultural leisure spaces for young footballers within the context of the changing local cultural landscape of Leicester and with reference to wider debates around racial integration and multiculturalism in late modern Britain.
\end{abstract}

Keywords

football, identity, inclusion, racism, resistance 
Introduction

Sport is central to the cultural fabric of late modern Britain and is a site in which the reconfiguration of old biological and newer cultural racisms have become manifest in explicit and more coded forms. These racisms are generated by and impinge upon sporting practice and encounters and work in complex and often contradictory ways, defining the parameters of sporting inclusion and exclusion differentially amongst different Black and Minority Ethnic (BME) groups across a range of intersectional indices, including gender, social class and religious affiliation (Kay, 2006; Ratna, 2007; Rowe and Champion, 2000; Scraton et al., 2005). Whilst racisms in sport are shaped by a range of historically inscribed power relations and relatively closed hegemonic practices and contribute to the reproduction of a series of social, economic and cultural inequalities, they are also consciously negotiated and contested in different ways across specific social formations and at specific historical junctures. The work of Burdsey (2006), Carrington (1998b, 1999), Ratna (2007) and Woodward (2004), all allude to the ways in which BME communities have enacted processes of physical, cultural and ideological resistance to racisms across a range of locally grounded sporting contexts in Britain with particular respect to cricket, boxing and football.

It is the aim of this article to build on these previous contributions and offer an original empirical and theoretically grounded contribution to the largely underresearched area of 'race', culture and identity in amateur football in England. In doing so, this article will draw in the first instance on quantitative survey based data to identify the extent, shape and scope of BME participation in amateur football clubs in Leicestershire. The article will then utilize the more qualitative narrative accounts of key research participants to contextualize the socio-historical development of BME football clubs as sites of active resistance to racisms and as symbols of positive cultural identity production and will illustrate further the ongoing cultural appeal of clubs of this kind to BME participants. The article will then move on to examine the purposeful and shifting role of some BME clubs and the emergence of newer 'multiethnic' clubs as facilitators of new inclusions and positive multi-cultural leisure spaces for young footballers from an increasingly diverse range of backgrounds. Finally, the article will contextualize these more empirical findings within the context of the changing local cultural landscape of the city of Leicester and with reference to wider debates around racial integration and multiculturalism in Britain.

Before moving on to examine the main findings of the study, it is important to first offer some clarification regarding the terminology used to describe ethnic groups throughout the article. The term Black and Minority Ethnic (BME) is used here as a broad descriptive marker to refer primarily to non-white communities, inclusive of indigenous and more recent in-migrant populations to Britain. The term is commonly employed in public policy, voluntary services and the social sciences in Britain and 
also in research examining ethnicity and sport (Long et al., 2009). In the context of this Leicestershire-based study the term BME is most likely to refer people of African, African-Caribbean, Indian, Pakistani and Bangladeshi heritage and people of dualheritage (see section below: the local context) and does not include White European or White Irish in-migrants whose participation in amateur football was outside of the initial focus of this research (see section below: the study and methods). The terms 'Black' and 'Asian' are also used to denote further ethnic sub-division of people of African and African Caribbean origin ('Black') and those drawn from Indian, Pakistani and Bangladeshi ('Asian') communities.

Categorizations of this kind are, of course, conceptually limited and subject to significant academic contestation. This is especially the case with regard to efforts to develop linguistically a terminology which is suitably nuanced to capture the commonalities and specificities of BME cultural identities and structural experiences whilst seeking to avoid ethnic reification or contributing to processes of political disempowerment (Hall and Du Gay, 1996; Modood, 1994). Nonetheless, the terms 'BME', 'Black' and 'Asian' (and 'White') were commonly cited and conceptually understood by all of the research participants to refer specifically to those ethnic groups as described above. In this respect, these categorizations are intended to provide a series of self-referencing explanatory markers of ethnic identity through which to examine the processes and experiences of BME participation in amateur football in Leicestershire. It is to an examination of the wider literature on 'race' and football in England to which the article now turns.

Research on 'race' and football in England

Academic explanations of the relationship between 'race' and English football have tended to focus on the elite echelons of the professional game. Initial academic inquiry emerged in the late 1970s and 1980s and featured a strong emphasis on identifying and explaining the incidence of overt forms of racist abuse targeting black players (Cashmore, 1982; Holland, 1996; Williams, 1992) and the role of 'far right' political groups in encouraging spectator racism at domestic football fixtures and in terms of support for the English national team (CCS, 1981; Williams, 1984). More recently, an emergent body of academic work has alluded to the complexity of English football spectator identities, with particular regard to the role of 'alternative' fan identities in challenging ideologies of 'closed nationalism' and overt expressions of racism and xenophobia and conscious attempts to shape support for the national team in ways which are more inclusive to BME fans (Carrington, 1998a; Perryman, 1999, 2002; Williams, 1999). A number of authors have also focused on the way in which specific domestic club supporter cultures generate symbolic meanings to do with tradition, place, and belonging, premised on the celebration of homogenously white and racially closed birthplace localisms (Back et al., 2001; Nash, 2000; Robson, 2000). For some authors, the historical legacy of spectator racism at professional football games has (along with issues of cost) contributed significantly to the relative paucity of BME fans attending live games (Williams et al., 2001a, 2001b) and has 
impacted negatively on the experiences of BME stadium communities in terms of incidents of racist abuse and racial harassment (Bains and Johal, 1998; Pinto et al., 1997).

More recent academic attention has shifted towards examining patterns of institutional closure apparent within national and local football governance and at professional football clubs in England (Back et al., 2001; Bains, 2005; Bradbury, 2001, 2010; Burdsey, 2004, 2007; King, 2004; Lusted, 2009). These new perspectives on 'race' and football in England illustrate the ways in which the hegemonic whiteness embedded within the football industry have shaped the parameters and scope of BME participation in the game through the operation of 'cultural passports' and the enactment of relatively 'closed' recruitment practices at all levels of the sport. Authors here have also identified a distinct lack of critical reflexivity and some deeply embedded cultures of resistance to more equitable change amongst the games key stakeholders. The relatively limited effectiveness of local, national and political initiatives designed to confront more obvious forms of racism and institutionalized patterns of racial exclusion in English football has also drawn critical attention from academics and from non-governmental bodies with a key interest addressing ongoing inequalities in the sport (Back et al., 2001; Bradbury and Williams, 2006; CRE, 2004; Hylton, 2009; IFC, 2003; Long, 2007).

Despite high levels of BME participation at the grassroots level of the game, issues of 'race' and amateur football in England has traditionally been an under-researched and relatively marginalized area of academic study. Research commissioned by the national Kick It Out campaign in West Yorkshire in 2000 revealed clear differences in the perceptions and experiences of racism in grassroots football between players of different ethnic backgrounds. The authors concluded that 'despite some confusion as to what constitutes racist behaviour, the research team were left in no doubt that it does occur and consequently stronger measures are needed to address it' (Long et al., 2001: 9). Similarly, research into the local game in Leicestershire (Bradbury, 2002) alluded to the continued existence of racialized tensions between players from different ethnic backgrounds. Findings reported in these geographically focused studies echoed concerns outlined in the Football Task Force report 'Eliminating Racism form Football' (1998) regarding the extent of - and lack of effective action against - racism in the amateur game. Interestingly, these concerns were premised on submissions made to the Football Task Force by the national Kick It Out campaign, localized anti-racism initiatives and prominent BME amateur clubs rather than by those involved in the national or local governance of the sport.

Beyond these more descriptive accounts of the extent and shape of racism in amateur football in England, the more ethnographically focused work of Westwood $(1990,1991)$ and Williams (1994) in football, and Carrington (1998a, 1999) in cricket are particularly instructive in identifying the social and cultural significance of BME sports clubs as sites of resistance to white sporting hegemonies through their role in offering increased opportunities for BME sporting participation within culturally 
distinct and discursively constructed 'black' (male) spaces. From these perspectives, BME sports clubs are positioned as a key cultural resource for BME communities which enable the positive construction and expression of specific ethnic, cultural and neighbourhood identities and enable increased community empowerment. More recently, the work of Burdsey $(2004,2006,2007)$ has further located the significance of (male) amateur clubs of this kind in terms of their functionality as 'symbols of community and cultural resistance, facilitating contingent cultural integration, and circumventing the normalisation of whiteness in mainstream amateur football structures' (Burdsey, 2006: 477). The particularities of the socio-historical development and function of clubs of this kind and their impact on shaping the trajectories of BME participation in amateur football is arguably better understood with reference to those locally grounded contexts from which they have emerged. It is towards providing some contextual background to the local racial demography and political and cultural structure of the city of Leicester to which this article now turns.

The local context

The county of Leicestershire is situated in the heart of the East Midlands of England and is an area of considerable social, economic and ethnic contrasts. Beyond the distinctly urban landscape of the city of Leicester, the county's majority population inhabit a range of socially and economically diverse residential settings, incorporating relatively affluent suburban locales, bustling market towns and 'sought after' village locations, as well as less economically advantaged former mining villages and rural farming communities. For the most part, these wider county based locations remain relatively untouched by patterns of post-war 'new Commonwealth' in-migration to Britain and remain homogenously and culturally White. In contrast, the social and cultural landscape of the city of Leicester has since the 1960s undergone a dramatic transformation and has both rejected and incorporated successive waves of 'settlers' from a range of ethnic backgrounds. Initiated by the 1962 Commonwealth and Immigration Act and greatly hastened from the late 1960s onwards by the influx of East African Asian in-migrant communities fleeing social, economic and political persecution in Uganda and Kenya, the 'new Commonwealth' population of Leicester had risen to 60,000 by 1981 (Martin and Singh, 2002). The rapidly changing racial demography of the city during this period engendered significant hostility towards new in-migrant communities. The city became a centre for National Front activity and the City Council in Leicester once advertised in the African press that no new minorities should come from Uganda to Leicester to join earlier arrivals (Martin and Singh, 2002).

By 2001, Leicester's more generationally embedded and increasingly diverse BME communities accounted for more than one-third (36\%) of the city's 280,000 strong residential population. In total, 'Indian heritage' groups account for the largest segment (72\%) of the local BME population which also features longstanding Pakistani, Bangladeshi and Black Caribbean communities, and, newer Black African, Kurdish and Iraqi asylum and refugee communities. The significant ethnic diversity of 
Leicester's inhabitants is not restricted to its (visible) BME communities. In the immediate post-Second World War period the city attracted sizeable numbers of Polish, Ukrainian and Serbian émigrés and in the 1990s accommodated refugee communities fleeing from the war-torn Balkans region and in more recent times has also experienced a steady influx of economic in-migrants from EU accession countries in Central and Eastern Europe.

The local housing ecologies of Leicester indicate a concentration of BME communities in specific locales to the immediate north and east of the city's commercial centre, including eight districts in which between 50 percent and 90 percent of local residential populations are 'Black' or 'Asian'. The racial demographic of these locales contrast sharply with those predominantly 'White' public housing estates that occupy points on the south and western periphery of the city boundaries and which feature prominently on national measures of social and economic deprivation (Neighbourhood Renewal Unit, 2004). These racially inflected residential settlement patterns are to some extent a historical consequence of the operation in the 1970s of some racially closed practices of public sector housing allocation in Leicester which consciously limited and actively discouraged East African Asian settlement in key 'White' estate locales. The consequent spatial distribution of Asian communities in areas in which affordable private sector housing is predominant and proximate to developing familial, social and economic support network has also further accentuated the dominant racial demographic in specific districts (Singh, 2005). However, it is also the case that many other districts in Leicester feature a much less rigidly defined and more fluid racial demographic, where between 10 percent and 50 percent of the local populace are drawn from a culturally diverse range of BME backgrounds and where 'White' residents are characterized less by their ethnic and cultural homogeneity. It is here also that many of Leicester's fast growing and relatively youthful 'dual heritage' population are resident. More than 5000 of the city's overall population are from ethnically mixed backgrounds amongst which more than one-half are aged 16 years old and below. These more 'multi-ethnic' districts include a number of working-class locales in and around the commercial centre of the city and in the shadow of the city's two universities as well as more affluent suburban neighbourhoods, where East African Asians feature especially strongly.

Over the past 30 years, the city of Leicester has slowly developed an international public image as a relatively successful 'multi-cultural' city where ethnic diversity in commerce and social life are positively promoted and valued. The most obvious indicators of the 'value' placed on ethnic diversity can probably be seen in the very public celebrations of religious and cultural festivals in Leicester, but there also strong signs that Leicester has developed a strong equal opportunities culture in employment - especially in the public sector - and in terms of political representation. Presently, 14 of the city's 30 local councillors are from Asian backgrounds and one longstanding local MP is Asian. Initial political progress in this respect was very 
much driven by the emergence of a powerful radical left ruling group within the local Labour party in the late 1970s and 1980s which aggressively pursued a series of racial equality policies designed to impact positively on the way in which local government infrastructure connected with - and delivered services to - the local BME population. This leftist political commitment (and political expediency) strongly cemented the power base of Labour in key ward areas of the city and has allowed the local authority in particular to assume a powerful and pivotal position as the key facilitator of issues of 'diversity management' in ways which have arguably prevented the kinds of community dissonance and resultant violent disturbances experienced more recently in the former 'mill-towns' of the northwest of England (Singh, 2003).

It is probably the case, too, that the steady transformation of Leicester as a so-called 'model' of multiculturalism has been assisted by the diversity of occupationally based identities in the city and by the social class and cultural backgrounds of Leicester's key minority groups. This is most apparent with reference to East African Asian 'twice migrants' whose significant pre-existing and transferable entrepreneurial acumen has helped establish a thriving Asian business community in the city with an emphasis on a range of local, national and trans-national service provision. The relative stability of the local economy over time in Leicester has also arguably promoted the process of integration and local acceptance rather more than has been the case in some other post-industrial towns in England where the impact of industrial recession has been felt more strongly and where historically embedded and rigidly defined 'local structures of feeling' have contributed to shaping more polarized versions of local 'race relations'.

However, it is also important to recognize that behind the very positive public image of 'multicultural Leicester' there exists some very real inter-ethnic tensions between different BME groups and a significant continuation of openly expressed racist sentiment in largely white enclaves. Further, it is probably also the case that in Leicester, as in some of the other major urban areas and provincial towns of England, the complex interplay between processes of institutionally enforced separation and voluntary cultural self-segregation has reduced the potential for - and realization of a more conjunctive co-existence between some BME and 'White' communities in some locales. It is against this complex and constantly shifting local cultural and political landscape that the lived experiences of BME and White communities has been 'played out' in the local societal and sporting arena. It is towards the main findings of the study to which this article now turns. The data presented here are drawn from a two-phase study of player, workforce and club development in amateur football in Leicestershire conducted by the author between February 2006 and September 2006. The study was commissioned by the Leicestershire and Rutland County Football Association (LRCFA) as part of an extensive information gathering exercise with amateur football clubs in the region to measure the impact of and help better inform key policies and practices designed to support club development. The research focus was also strongly supported and designed in collaboration with the 
Leicestershire and Rutland Local Football Partnership (LRLFP) Equity and Inclusion sub-committee: a group featuring representatives from the LRCFA football development team and from local BME clubs. Central to the aims of the study were to establish an empirical marker for levels of BME participation in the game as players, coaches and management committee members at clubs and to identify issues which might impact on the access and sustainability of experiences of BME participants.

Phase one of the study involved a questionnaire based survey of club secretaries at 662 amateur football clubs affiliated to the LRCFA playing competitive football within organized league structures. In total, the research yielded completed responses from a broadly representative sample of 246 local football clubs: a 38 percent response rate. The sample group of respondent clubs featured an estimated 763 active teams, 13,300 players, 638 qualified coaches, and 1455 management committee members. Whilst survey work of this kind can never provide a wholly accurate picture of events or local processes, the author recognizes fully the difficulties involved in moving from assertions from individual respondents to concrete analytical conclusions and has sought to avoid making any overly mechanical assertions in this respect. Further, questionnaire design and data analysis was undertaken in lieu of the authors significant ethnographic experiences of local football governance infrastructures and operational practices at amateur football clubs and with some significant knowledge of previous academic and evaluative studies around 'race' and amateur football in Leicestershire and in other locales in England (Bradbury, 2002; Burdsey, 2006; Long et al., 2001; Westwood, 1990, 1991; Williams, 1994).

Phase two of the study involved conducting more focused semi-structured interviews with club 'workers' at 10 case study amateur football clubs. Interviewees were characterized by their diversity across axis of age, gender, ethnicity and social class and in each case had progressed from playing the game to assume football coaching or management positions and/or senior administrative roles at their clubs over time. All case study clubs had been operational for between 22 and 40 years respectively, competed across a range of 'ability' tiers within the local football pyramid, and facilitated a range of (mainly) male and female adult and youth football provision. Whilst two higher ranking case study clubs were situated in semi-rural locales to the north and west of the county, all other case study clubs had a much stronger geographical and cultural connection to the city of Leicester and the immediate surrounding suburban locales.

The use of semi structured interviewing techniques encouraged interviewees to provide naturalistic and personalized accounts of their experiences of the local game in their own terms of reference and produced significant in-depth textual data to this end. The flexibility of this 'conversation with purpose' approach was also designed to prioritize and place a much more central emphasis on the value of the experiential knowledge of interviewees and to (re)position them as the 'knower' within this interactive discourse. The personalized accounts of interviewees both corroborated 
and challenged the preconceptions of the author and encouraged a more subtle, nuanced and contextual interpretation of these locally grounded narratives. This approach to data collection also encouraged the author to exhibit some significant critical reflexivity in terms of the way in which his own (white, male) socio-cultural and (middle-class) professional positioning might impact on and shape the nature of qualitative information elicited from the interview process.

Nonetheless, the author sought to move beyond those epistemologically informed methodological practices which prioritize 'identity symmetry' as a means of accessing the 'authenticity' of personal experience and generating more 'truthful' representation. It is the contention here that such approaches rely heavily on a series of essentialist assumptions and homogenizing tendencies and probably overstate the rigidity of insider/outsider binaries across fissures of ethnic difference and underplay the relative fluidity of identity constructions of researchers and research participants across a range of structural and cultural intersections. Further, the totalizing principles embedded within such approaches probably also underestimate the potential for the agency of research encounters to contribute to the production of multifarious and sometimes conflicting narratives from individuals experiencing similarly shared exclusions and of the capacity of the interview dynamic to produce a series of 'situated and contingent creative multiple mappings of a complex and multi-faceted reality of realities' (Rhodes, 1994: 241). In this latter respect, the author was acutely conscious to actively negotiate mutual perceptions of commonalities and difference emergent within interactional process of interview situations whilst simultaneously recognizing the inherent power imbalance embedded in the social distance between researcher and researched.

There was, too, a number of important local contextual factors which helped the author to overcome potential 'gate-keeper' issues and encouraged the production of extensive and purposeful narratives in a safe and supportive discursive space. The initial scope and focus of the research emerged from a strongly collaborative process involving the LRCFA and representatives from BME clubs whose ongoing consultative input was maintained throughout the duration of the research project. Further, almost all interviewees (including all BME interviewees at Leicester based clubs) were known to the author (and, the author, to them) prior to the interview process through a longstanding shared involvement in a prominent local footballbased anti-racism initiative, through previous $(\mathrm{PhD})$ research collaboration and through the authors social and residential connection to 'multi-cultural' Leicester and regular presence at a range of local community and football events at which interviewees were often present. It is to an examination of the empirical findings generated by this research process to which this article now turns. 
Phase one survey findings

i) Overall representation of BME participants

Phase one survey results showed strong levels of overall representation of BME players (14.9\%) at clubs in the sample group: a figure proportionate to 2001 Census data for the wider BME population of Leicestershire (15\%). However, this overall figure disguised strongly differentiated patterns of participation in playing the game across axis of age, gender, ethnicity and religion. For example, black players featured strongly in the local game $(5.2 \%)$ relative to their representation within the local population (1.1\%), and in broadly equal measure across male and female adult and youth football provision. Conversely, the general under-representation of Asian players (7.1\%) relative to local population demographics (11.9\%) was a markedly adult phenomenon and was counter-balanced to some extent by strong levels of active participation at clubs amongst young male players drawn from culturally and religiously diverse Asian communities.

Survey findings also drew attention to the general under-representation of BME participants as qualified coaches (10.2\%) and management committee $(6.3 \%)$ at clubs in comparison to wider population figures for BME communities in Leicestershire (15\%). Findings here were also differentially marked across of axis of gender, ethnicity and religious background. For example, almost all BME coaches and management committee members were male and were involved in clubs that focused on male adult and/or male youth provision. Further, most Asian coaches and management committee members were Sikh, with relatively few of the football 'workforce' at clubs from Hindu or Muslim religious backgrounds.

ii) Distributional spread of BME participants

Survey findings also alluded to the strongly differentiated distributional spread of BME players, coaches and management committee members at clubs in our sample group. In total, two-thirds (66\%) of clubs in the sample group featured none (30\%) or fewer than 10 percent of players (36\%) from BME backgrounds. Clubs here tended to be situated in suburban or semi-rural locales within the wider county of Leicestershire where there are smaller BME populations. In contrast, around onethird (34\%) of clubs in the sample group featured 11 percent or more BME players, including a significant cluster of clubs situated in and around the city of Leicester which featured between 25 percent and 50 percent of players from BME backgrounds and five clubs where more than 75 percent of players were from BME backgrounds. Whilst black and dual heritage male players featured prominently across a broad spread of this cohort of more ethnically mixed clubs, this distributional spread was much less pronounced amongst Sikh and Muslim male players or amongst BME female players. Similarly, relatively few clubs in the overall 
sample group featured coaches (22\%) or management committee members (16\%) from BME backgrounds.

iii) Distributional concentration of BME participants

BME participation as players was strongly concentrated at just five clubs situated in the city of Leicester. Collectively these BME clubs provided significant opportunities for male based football provision, hosting 10 adult teams, 24 'full-sided' youth teams and 25 'mini-soccer' children's teams. In total, these five clubs accommodated 790 registered players of which 86.8 percent were drawn from BME backgrounds: almost two-fifths (38\%) of all BME players participating in the game at all clubs in our sample group. Further, almost all coaches (89.2\%) and management committee members (98.2\%) at these five clubs were from BME backgrounds: almost two-thirds (64\%) of the total BME 'workforce' at all clubs in our sample group. The relative absence of opportunities for female participation as players or as part of the 'workforce' at BME clubs was notable. Clubs of this kind were clearly a 'male space'.

There was significant heterogeneity between - and in some cases within - these five BME clubs in terms of the dominant ethnic and religious demographic of participants and the assumed cultural identity of clubs. Whilst one club exhibited a longstanding cultural connection to local Black Caribbean communities, the other four BME clubs drew mainly on participants from Leicester's diverse Asian communities. Here, there was a clear split in terms of the dominant religious affiliation of participants and the identities of clubs, incorporating two Sikh clubs, one Hindu club, and one Muslim club. In the latter case, almost two-thirds (64\%) of all young Muslim males playing the game in Leicestershire were doing so at this one club. However, the religious make-up of players at this particular club arguably resulted less from any overt forms of religious identification on the part of the club (in contrast to, for example, Leicester's two Sikh clubs) and was much more informed by some geographically specific and politically conscious recruitment processes targeting young players in some of the most deprived wards in Leicester, which featured significant Pakistani, Bangladeshi and Somali communities. It was also the case that this particular club featured the most ethnically and religiously diverse mix of young players of all BME clubs. It is towards a more contextualized and layered account of the processes and practices that have historically informed the shape, scope and experiences of BME inclusion in football at BME clubs and at newer 'multi-ethnic' clubs to which this article now turns.

Phase two interview findings

i) Racisms, resistance and safeguards at BME clubs

All five BME clubs in our sample group were formed between 1968 and 1979 by young males from families of first generation in-migrants from the British Commonwealth. In the city of Leicester, as in many other major industrial areas in England during this period, rapidly changing local racial demography's engendered 
significant expression of resentment and hostility on the part of indigenous White communities towards newly arrived and recently settled BME communities. The expression of these wider societal racisms and embedded oppositions to racial integration were especially evident within the culture and practice of amateur football, where club affiliation was (and, often, still is) deeply rooted within heavily masculine and homogenously White neighbourhood and kinship networks. These socially constructed patterns of organization embedded within pre-existing amateur football networks contributed significantly to shaping the initial parameters of inclusion and exclusion of BME young males in the game locally and acted in part as an accelerant towards the formation of clubs from within BME social networks. Two Asian interviewees at BME clubs articulate further this correlative process and offer some insight into the way in which local religious and cultural institutions became central venues for football and community development in the city of Leicester:

'It was difficult for us to go and knock on [White] clubs doors and say 'can we play?' They would look at you and say 'hang on, how can you play, you're Asian'. That's the reason why all of these [BME] clubs were set up in the first place. Because they couldn't get into White teams'. (Vice-Chair, BME club)

'Traditionally, there's never been much access for Asian people getting into White teams, in fact it's been very hard, very rare, you'd be very lucky if that happened. It limited a lot of players in terms of where they could play and a lot just dropped out. But there was a firm interest in football amongst young people, attached to their sort of gangs, you know, or the Sikh temples and Hindu temples and so on. That's how it all started. (Club secretary, BME club)'

Beyond the historically embedded processes of racial closure alluded to above, the amateur echelons of the game in Leicestershire has also been a site in which more obvious forms of racist behaviour has been (and, to some extent, continue to be) commonplace. Previous research into player and spectator behaviour in local football in Leicestershire (Bradbury, 2002) found that an overwhelming majority (82\%) of local club secretaries felt there was at least 'a small amount' of racism in the local game, whilst a further 10 percent of respondents felt that racism was 'considerable' or was apparent 'throughout local football'. More than one-third (36\%) of club secretaries felt that 'racist remarks are sometimes aimed at ethnic minority players by opposition players and spectators' and a further 16 percent conceded that racist remarks emanate, on occasions, from their own team and supporters. The interviewee below recounts examples of overt racist abuse and harassment at matches involving one BME club over time:

'We've had a group of supporters behind the goal shouting 'Get on with it, Nigger'; 'You should stick to robbing cars'; 'You fucking Paki' and so on. It's probably more [the] spectators than players, parents as well as young people. It happens more when we've played out of town, even more abuse there than when you play in the White inner city areas'. (Club secretary, BME club) 
Notably, the interviewee above refers explicitly to the spatiality of the incidence of racist behaviour by opposition players and supporters across distinctly racialized regional geographies. The comments also reference the commonality of racist expression and racialized antipathies across generational cohorts and the conscious utilization of racial epithets designed to describe and demean players from BME backgrounds, and, in the case of young black males, to mark them out as a kind of dangerous, criminal 'other'. Whilst racist abuse of this kind is premised on key biological and (imagined) cultural referents, the following comments from one interviewee at a prominent Black-Caribbean club allude to the more recent practice of a much more subtle, nuanced and codified form of cultural racism, which is designed (and understood) to mark out some contingent parameters of belonging and cultural inclusion within local football and, concomitantly, within local societal relations:

'More recently, opposition players haven't used a swear word, but they have been derogatory and flippant about people's cultural background, about cultural modes of dress and behaviour patterns. Really demeaning and derogatory behaviour. I think there is a subtle line between that kind of behaviour and the out and out rudeness and bullishness that may take place between white players. When you have black players involved they [white players] have that condescending tone. (Committee member, BME club)'

Whilst the perception of racism on the part of those who witness or experience it as such is not a necessary of sufficient condition of its existence, it is important to locate the interpretation of its meaning within the contextual layers and local settings in which these racialized actions are performed and acted out (Long and McNamee, 2004). In this respect, the behaviours referred to above can be read as a distinctly situated and consciously strategic response by White players designed to offend liberal sensibilities and to be symbolically oppositional to ideas of 'progressive' multicultural Leicester as embodied within the dominant demographic make-up and identities of BME clubs. Behaviour of this kind also alludes to themes of intentionality and purpose and the way in which more nuanced cultural racisms are increasingly affected through the use of racially coded signifiers specifically designed to reify cultural difference and encourage racialized antagonisms in a more consciously 'disguised' form. Whilst the interviewee understands and articulates these behaviours as having racist undertones, identifying this behaviour as such, within legal or disciplinary frameworks, is much more difficult, and has become a constant source of tension between BME clubs, match officials and the local governing body.

BME clubs were also conceptualized as sites which enabled physical solidarity and collective safeguards against these historically prevalent and ongoing expressions of racism at the local level and to provide a safe and supportive environment for players from BME backgrounds. One interviewee comments further in this respect: 
'It's because that's where Asian or black players feel comfortable, welcome, and they feel safe. I know last season there was this Asian boy playing for a White team. He was getting called racist names, not from his own players, but the opposition players and the parents. Nothing was done about this and he's left and he's gone to [a BME club]. That's the reason why Asians stay at the clubs where they feel comfortable, they're not going to get called names. If something happens, if something kicks off, the whole club will stick up for you, so you're not just on your own like you would be at a White club where you're left thinking, 'I play for this team, why the hell am I being singled out'. (Club secretary, BME club)'

The comments above also highlight a kind of sliding scale of support for Asian players at some clubs outside of BME social networks in Leicester. That is, whilst in this case, players and coaches at some predominantly White clubs might be keen to implement an 'open door' policy to player recruitment and welcome the initial involvement Asian players, there is perceived to exist an apparent absence of positive protection for such players when racism occurs, in comparison to that which is afforded at predominantly Asian clubs.

The cultural identity and appeal of BME clubs

In addition to enabling a safe and supportive physical environment in which to encourage greater BME sporting participation, BME clubs also performed an important socio-cultural function for their constituent communities in Leicester. In particular, these clubs had become positioned as a highly visible cultural resource and symbolic marker for the construction and expression of specific ethnic and religious identities. The work of Burdsey (2006), Carrington (1998b, 1999), Westwood (1990) and Williams (1994) is particularly instructive in illustrating the ways in which BME sports clubs can act as sites of cultural resistance to wider societal racism and perceived community injustice through involvement in victories against perceived historical oppressors and the celebration of BME sporting achievement. From this perspective, BME sports clubs are understood to represent discursively constructed and distinctly racialized symbolic spaces within which participation has come to constitute a form of local community politics and community empowerment. The historical and cultural significance of clubs of this kind as sites of practical and symbolic resistance to white sporting hegemonies was strongly alluded to by interviewees at BME clubs in Leicester. The interviewee below offers a consciously political construction of BME club identities which conjoins notions of cultural identity production with community collectivism and provides a powerful overview of the initial symbolic function and ongoing cultural relevance of BME clubs in this respect:

'It's our history, it's embedded in 'black' people's struggle. It's about the ability for 'black' people to mobilize themselves and to say to the wider world 'look, we can organize ourselves, we can bring about equality and self-improvement'. It's the identity of those [BME] clubs and the identity of the people. These clubs set 
themselves up to create their own identity to establish themselves as a force and to continue that sort of common purpose. 'Black' people need to have that identity, and all these clubs identify with a specific identity, you know, religious, cultural, a common identity for the community'. (Vice-Chair, BME club)

The identifiable (and identifiably different) social, cultural and religious attachments of BME clubs were understood to have engendered significant ongoing cultural appeal and to continue to inform the initial participation trajectories of BME youth cohorts and the sustained organizational commitment of older BME participants. This was especially the case at those Asian clubs which had strong developmental connections to specific religious places of worship and which promoted opportunities for familial and cultural continuities and faith-based socialization. Interviewees at Leicester two Sikh clubs comment further:

'We don't have a major problem recruiting players. A lot of people involved in the club are second and third generation [club] players anyway. The club itself has been going for a long time and the people who have played for the club have got sons and grandsons and they want them to stay with the same club they played for. Because the first lot of players were Sikhs, the follow-up are Sikhs. It's just how it has always been from the start'. (Committee member, BME club)

II think a lot of people are committed to their club they identify with. At [our club] the management committee have always been around in the community. The sponsors, the committee members and the players all come from one sort of background. I would feel uncomfortable sitting on a club's committee the other side of Leicester where I didn't know the players or the sponsors. It wouldn't be relevant'. (Club secretary, BME club)

Whilst interviewees at Asian clubs reflected on their conscious attempts to avoid the kinds of racial closure which had previously impacted on their own personal experience of the game and made explicit claims to informal practices of 'equality of opportunities' with regard to player recruitment, the demographic make-up of clubs of this kind maintained some degree of permanence over time as measured by the ethnic and religious homogeneity of male adult and male youth players. It is probably the case here that whilst the strongly religious identities of Asian clubs has strengthened the cultural and generational bond between existing club members and has provided an important and historically consistent conduit into the local game for key marginalized communities, clubs of this kind probably also have relatively limited wider appeal to potential players from other religious or more secular backgrounds. It is probably also the case that the continuation of some deeply embedded racist sentiment and residual cultural stereotypes within some White communities in the region has further gravitated against greater sporting integration in this respect. One interviewee at a mainly Hindu club reflects further: 
'Generally, you've got the stereotype thing, because we're an Asian club. In the past we have tried to attract more White players but they don't want to play with the Asian community. Some of the White players think that we don't know how to play football, you know, 'we don't want to go and play for Paki teams'. We've had those sorts of things, mainly stereotypes, 'they can't play football', all of that stuff'. (Club secretary, BME club)

New inclusions and multi-ethnic leisure spaces

Whilst all BME clubs performed an important symbolic and practical function for BME sporting communities, in some cases, they also increasingly provided an ideological and physical space in which the production of new, youthful, and dynamic, multiethnic identities could be formulated and realized to varying degrees through the provision of valuable participation opportunities for players from an increasingly broad range of ethnic backgrounds. The tendency towards attracting more culturally diverse young players was most pronounced where overt religious affiliation was less centrally embedded within the socio-historical development and cultural identities of clubs. At two BME clubs in particular, there was a strong sense that processes of player recruitment were consciously designed to reflect a wider ethos of multi-cultural service provision for disenfranchised communities, that includes and goes beyond - football provision. Interviewees at these two clubs comment further:

'I think a lot of people like to play for [the club] because it gives them self worth and it's not just about football, it's about family, people unifying themselves, the different races, the different cultures. But that's what we aim to do, give hope basically, you know, to people who may not be able to go to any other club and just walk in there, we develop the person and we give everybody an opportunity. We aren't selective like other clubs'. (Vice-Chair, BME club)

[The club] is unique. Whilst all the people on the management committee are from the Black African-Caribbean community there has always been a diverse mix of players, Asian, White, Black-Caribbean, Black-African and Eastern European players now. The club is different. We are not a bland conformist club. We have a rich culture within the club. It has always been a rich mix'. (Committee member, BME club)

In both of the above cases, there exists a conscious self-positioning of these clubs as different to - and more inclusive than - other White and (mainly Asian) BME clubs. Whilst these claims are borne out to some significant extent by survey findings which allude to the culturally diverse make-up of young players at these clubs, it is important to locate these comments within the distinct local context from which they have emerged. In this case, with at least some recognition of the often fierce rivalries played out between BME clubs both on and off the pitch in Leicester and with regard to, often, 'heated' competition regarding the recruitment of youth players, access to 
scarce economic resources and symbolic local pride. It is probably also the case here that these particular BME clubs have some significant appeal to specific cohorts of young White players with a stronger connectedness to the everyday lived experiences of some spatially focused urban settings in multi-ethnic Leicester.

On this latter score, initial survey data also identified the more recent development of a small cluster of clubs situated in and around the city of Leicester where between 25 percent and 50 percent of players were from BME backgrounds. These clubs focused solely on male and/or female youth football provision and featured both male and female coaches and management committee members from White and BME backgrounds. These clubs had much shorter histories than BME clubs and had developed less as a response to racism or as a conscious self-mobilization of BME sporting identities and more out of general concerns to combat the apparent lack of football provision for young people in specific locales in and around the city of Leicester. Whilst the demographic make-up of participants and the cultural identity of these clubs was considered to be of secondary relevance to the more central aim of the provision of co-ordinated football opportunities for geographically specific cohorts of young people, interviewees reported on positively encouraging and successfully attracting the involvement of players and club 'workers' from a more diverse range of ethnic backgrounds than had been the case in the past:

'There are more ethnic minority children playing with us than there were before, and again you've got to encourage that. I think it has gone that way over the last couple of years. The children are there on merit, you know, Black, White, Asian, you name it, they're there on ability. These boys and girls deserve the opportunity and we certainly make sure that we give them that. (Chair-person, male youth club)

I will say that where we are based there is a high Asian population. To be honest, we don't have any barriers or anything, I mean if they're good enough to play and they want to play, we welcome everybody. That's the way we are. We do have a mix of managers as well. Male, female, Asian managers as well and they're great guys, you know. (Club secretary, male/female youth club)

The increasing ethnic heterogeneity of players and coaches at clubs of this kind strongly reflected the changing demographic landscape in Leicester. This is especially the case with regard to processes of public sector housing re-allocation which facilitated the residential fragmentation of inner city Black Caribbean communities in the 1980s and more general patterns of social mobility experienced by East African Asian cohorts over the past 30 years and whom feature strongly within residential populations in more affluent suburban locales in and around the city. The interviewee below reflects on the gradual residential dispersal of Leicester's longstanding black and Asian communities over time and the consequent impact on the broadening distributional spread of opportunities for BME participation at newer 'multi-ethnic' clubs: 
There's more of a spread of ethnic minority players amongst the young ones because of the sort of concentric movement of the Asian population or the AfroCaribbean population means that some of them move into predominantly White areas. So therefore they join the clubs in their areas basically, they've grown up with the White kids and adopt lifestyles and get acquainted in that way basically. (ViceChair, majority BME clubs)

The more focused accommodation of newer, mainly African heritage, asylum and refugee communities in specific urban locales in Leicester in the 1990s had also informed the shifting racial demographic of clubs in some cases. This was especially the case at one club situated an area of significant social and economic deprivation which had experienced the gradual settlement of new displaced 'black' communities in recent years: the interviewee below reflects on the impact of shifting local racial demography's on the make-up of one club:

The make-up of the community has changed and so has the club with it. We've had a lot of Somali refugees in the area and some of those lads are getting involved in the club. I think we've got more black children than Asians at the moment in the team. I've seen the club change in the last few years, [the area] has kind of been settled with new communities from different nationalities, whatever you like, that's basically what's happened, it's been a natural thing rather than a conscious effort. (Chairperson, male youth club)

Whilst the above comments reference the impact of shifting residential and settlement patterns in facilitating the transition from being predominantly 'White' clubs to becoming more ethnically 'mixed' clubs over time, it is probably also the case that club coaches and managers here have operated a much more racially inclusive and socially democratic approach to player recruitment than was (and, in some cases, still is) exhibited by other predominantly White clubs in the past. This is especially the case where key figures within clubs have exhibited distinctly socialistic intentions towards enabling increased sporting opportunities for some of the regions least affluent and most marginalized communities and where clubs have sought to address some deeply embedded and distinctly racialized gender inequities in accessing football participation. Clearly, player recruitment here is also undertaken with significant local knowledge and from a relatively mixed pool of local youngsters for whom multi-ethnic friendships and social connections are increasingly commonplace, at least, within distinctly 'classed' environments. The extent to which these clubs are able to offer the kinds of safeguards against racism afforded to young BME players at more strongly BME clubs is a little less clear. However, it is likely that clubs of this kind, especially those situated in more economically deprived districts and which focus on male youth provision, will probably convey a sporting representation of local 'estate' nationalisms premised on the complex interplay of 'race', class, locality and the 'performance' of youthful masculinities within these settings. 
On the basis of the analysis presented in this article it would appear that levels of BME inclusion in amateur football in Leicestershire were markedly mixed. Whilst BME participants featured strongly as players, especially amongst male youth cohorts, there was a more general under-representation of coaches and management committee members drawn from BME communities. Further, BME inclusion in the local game was strongly differentiated across intersectional axis of gender, generation, ethnic and religious background and was especially concentrated at a relatively small cluster of historically embedded and prominent BME clubs and at newly emergent 'multi-ethnic' clubs in specific locales in the city of Leicester. These patterns of BME inclusion in organized football in Leicester were intrinsically linked to the local socio-historical and cultural context in which they have been 'played out'. In particular, the specificities of in-migration trajectories and spatially focused residential settlement patterns of BME communities from the 1960s onwards and experiences of racially inflected institutional closure and more openly expressed racial hostilities from indigenous White communities in the local societal and sporting arena. These factors contributed significantly to shaping the initial parameters of BME inclusion in the local game and acted as an accelerant to the formation of clubs from within BME community and religious networks. The continued appeal of BME clubs can be understood in part as a conscious physical safeguard against the ongoing realities of multiple expressions of racisms still evident within the local game. However, it is also the case that BME clubs continue to exhibit a strong cultural appeal to younger and older BME participants and act as a conduit for the practice of generational, cultural and religious continuities and as a symbolic space in which positive sporting and societal representations of BME communities can become realized. This is not to suggest that clubs of this kind are sites of cultural separatism or of the kinds of voluntary self-segregation referenced within the politically dominant 'parallel lives' thesis emergent from investigations into racial disturbances and community dissonance in northern industrial England in 2001. Such thesis underplay the existence of underlying structural power dynamics and the divergent manifestations and different contexts in which racism operates at the local level and mistakenly assume egalitarian access to social, economic and cultural resources with which to challenge and overcome processes of racialized exclusion. Indeed, BME clubs in Leicester have arguably encouraged increased sporting and societal integration through their role in enabling the provision of valuable participation opportunities in organized football for a range of marginalized communities for whom access to local competitive football infrastructures has been historically limited. Further, the kinds of racial closure that had mediated their experiences of the local game. The tendency towards the increased inclusion of a more cultural diverse range of players was most pronounced where overt religious affiliation was less centrally embedded within the socio-historical development and cultural identity of clubs and where key 'drivers' expressed highly politicized and more deeply intentional socialistic philosophies which positioned clubs as facilitators 
of multi-ethnic service provision for youth communities. It was at these latter BME clubs, and at newly emergent 'multi-ethnic' clubs, that targeted recruitment processes had also been successful in engaging young players drawn from Leicester's most recent in-migrant cohort of globally displaced asylum and refugee communities resident in some of the most socially and economically deprived districts in the region. The willingness of young people within some spatially focused and racially mixed networks in urban Leicester to actively extend social and sporting connections with players from a diverse range of ethnic backgrounds might suggest that clubs of this kind have come to occupy a site in which meaningful and equitable racial integration is being positively enacted at least within some distinctly generational, classed and highly localized settings. It is here, too, that the potential for the development of new, youthful, and dynamic, multi-ethnic identities seemed especially apparent and was most likely to reflect, speak back to, and impact upon, the changing local landscape from which they emerged. To this end, these kinds of clubs might be understood to offer a practical and ideological 'third space' (Bhabha, 1990a, 1990b) in which the potential for new diverse inclusions and interactions might contribute to the production new culturally hybrid identities premised on shared social, cultural and sporting habitus (Bourdieu, 1986) of youthful populations drawn from specific multi-ethnic locales. The potential for - and greater realization of increased and more equitable opportunities for BME inclusion in the cultural space of local club football cannot be divorced from the wider structural dynamic and racial politics of the city of Leicester. In this respect, the uniqueness of in-migration trajectories, the relative fluidity of local economies, and the significant cultural (and socio-economic) diversity within local White and BME communities have all impacted positively on the shape of local 'race-relations' across a range of spheres of local social life, including football. These factors have also contributed to the relative lack of strong versions of 'neighbourhood nationalisms' (Back, 1996) and less rigidly defined 'local structures of feeling' (Taylor et al., 1996; Williams, 1977) amongst local populations than is probably the case in many more ethnically polarized locales in the Midlands and the North of England where attitudes to 'race' have been much less malleable over time and where their exists a deeply embedded cultural resistance to the inclusion of BME (especially Asian Muslim) communities within local social relations. Further, the longstanding 'multi-cultural' political project initially engineered and largely sustained by the electorally dominant Labour party in Leicester and the pivotal and progressive role of the local authority in pursuing conjunctive policies of racial equality and cultural recognition has probably also better enabled the process of 'diversity management' in the local societal and sporting arena than has been the case in other locales nationally. Indeed, it was notable that many of the 'workforce' at BME clubs and multi-ethnic clubs also held paid positions within sections of the local public and voluntary sector concerned with the equitable delivery of services and social provision to local communities and were familiar with - and supportive of - the philosophy and practice of equal opportunities policies to this end. Clearly, these philosophies and practices had significant transferable relevance and had been utilized as a guiding mechanism through which 
to engender the provision of positive multi-cultural leisure spaces for young footballers from culturally diverse backgrounds. It is against the broader social and political backdrop of 'race relations' in England and the more geographically (and culturally) specific locally grounded context of 'multi-cultural' Leicester that this study has examined and sought to contextualize the shape and scope of BME inclusion in amateur football in the region.

\section{References}

Back L (1996) New Ethnicities and Urban Culture: Racisms and Multiculture in Young Lives. London: UCL Press.

Back L, Crabbe T and Solomos J (2001) The Changing Face of Football: Racism, Identity and Multiculture in the English Game. Oxford: Berg.

Bains J (2005) Asians Can Play Football: Another Wasted Decade. Leicester: University of Leicester.

42 International Review for the Sociology of Sport 46(1)

Bains J and Johal S (1998) Corner Flags and Corner Shops: The Asian Football Experience. London: Phoenix.

Bhabha H (1990a) The third space - interview with Homi Bhabha. In: Rutherford J (ed.) Identity, Community, Culture, Difference. London: Lawrence and Wishart, 207221.

Bhabha $\mathrm{H}$ (1990b) Interrogating identity: The post-colonial prerogative. In: Goldberg D (ed.) Anatomy of Racism. Minneapolis: University of Minnesota, 183-209.

Bourdieu P (1986) The forms of capital. In: Richardson J (ed.) Handbook of Theory and Research for the Sociology of Education. Westport, CT: Greenwood Press, 241258.

Bradbury S (2001) The New Football Communities: A survey of professional football clubs on issues of community, ethnicity and social inclusion. SNCCFR, University of Leicester.

Bradbury S (2002) A survey of local football clubs affiliated to the Leicestershire and Rutland County FA: Issues of racism, ethnicity and player and spectator behaviour in local football. SNCCFR, University of Leicester.

Bradbury S (2010) It's not as simple as black and white: Challenging racisms in professional football through locally grounded multi-agency collaboration. In: Long J, Hylton K (eds) Challenging Racism in Sport. London: Routledge.

Bradbury S and Williams J (2006) New Labour, racism and 'new' football in England. Patterns of Prejudice 40(1): 61-82. 
Burdsey D (2004) Obstacle race? Race, racism and the recruitment of Asian professional footballers. Patterns of Prejudice 38(3): 279-299.

Burdsey D (2006) No ball games allowed? A socio-historical examination of the development and social significance of British Asian football clubs. Journal of Ethnic and Migration Studies 32: 477-496.

Burdsey D (2007) British Asians and Football: Culture, Identity and Exclusion. London. Routledge.

Carrington B (1998a) Football's coming home - but who's home and do we want it? Nation, football and the politics of exclusion. In: Brown A (ed.) Fanatics! Power, Identity and Fandom in Football. London: Routledge.

Carrington B (1998b) Sport, masculinity and black cultural resistance. Journal of Sport and Social Issues 22(3): 275-298.

Carrington B (1999) Cricket, culture and identity: An ethnographic analysis of the significance of sport within black communities. In: Roseneil S, Seymour J (eds) Practising identities: Power and Resistance. London: Macmillan,11-32.

Cashmore E (1982) Black Sportsmen. London: Routledge.

Center for Contemporary Studies (CCS) (1981) Football and the Fascists. London: CCS.

Commission for Racial Equality (CRE) (2004) Racial Equality in Football. London: CRE.

Football Task Force (1998) Eliminating Racism from Football: A Report by the Football Task Force Submitted to the Minister for Sport. London: The Football Trust.

Hall S and Du Gay P (eds) (1996) Questions of Cultural Identity. London: SAGE.

Holland B (1996) Kicking racism out of football: An assessment of racial harassment in and around football grounds. New Community 21(4): 567-586.

Hylton K (2009) Race and Sport: Critical Race Theory. London and New York: Routledge.

Independent Football Commission (2003) Annual Report. London: IFC.

Kay T (2006) Daughters of Islam: Family influences on Muslim young women's participation in sport. International Review for the Sociology of Sport 41(3/4): 357373.

Bradbury 43

King C (2004) Offside Racism: Playing the White Man. Oxford: Berg. 
Long J (2007) The Independent Football Commission and diversity in football. Leisure Studies Association Newsletter 78: 18-19.

Long J, Hylton K, Spracklen K, Ratna A and Bailey S (2009) Systematic review of the literature on Black and Minority Ethnic communities in sport and physical recreation. Carnegie Research Institute, Leeds Metropolitan University.

Long J, Hylton K, Welch M and Dart J (2001) Part of the Game. A report prepared for Kick It Out for the Centre of Leisure and Sport Research at Leeds Metropolitan University.

Long $\mathrm{J}$ and McNamee $\mathrm{M}$ (2004) On the moral economy of racism and racist rationalizations in sport. International Review of the Sociology of Sport 39(4): 405438.

Lusted J (2009) Playing games with 'race': Understanding resistance to 'race' equality initiatives in English local football governance. Soccer and Society 10(6): 722-739.

Martin J and Singh G (2002) Asian Leicester. Stroud: Sutton Publishing.

Modood T (1994) Political blackness and British Asians. Sociology 28(4): 858-876.

Nash R (2000) Contestation in modern English professional football. International Review of the Sociology of Sport 35(4): 456-486.

Neighbourhood Renewal Unit (2004) Indices of Deprivation 2004 for Super Output Areas. London: Office of the Deputy Prime Minister.

Perryman M (ed.) (1999) The Ingerland Factor: Home Truths from Football. Edinburgh and London: Mainstream Publishing.

Perryman M (2002) Ingerland Expects: Football, National Identity and the World Cup. London: Institute for Public Policy Research.

Pinto T, Drew D and Minhas N (1997) Sheffield Divided or United? A Study of 'Race' and Football. Sheffield: Sheffield Hallam University.

Ratna A (2007) A fair game? British Asian females' experience of racism in women's football. In: Magee J, Cauldwell J, Listone K, Scraton S (eds) Women, Football and Europe: Histories, Equity and Experiences. Oxford: Meyer and Meyer Sport Ltd, 7796.

Rhodes P (1994) Race of interviewer: A brief comment. Sociology 28(2): 234-249.

Robson G (2000) No One Likes Us, We Don't Care: The Myth and Reality of Millwall Fandom. Oxford: Berg. 
Rowe N and Champion R (2000) Sports Participation and Ethnicity in England: National Survey. London: Sport England.

Scraton S, Cauldwell J and Holland S (2005) Bend it like Patel: Centring 'race', ethnicity and gender in feminist analysis of women's football in England. International Review for the Sociology of Sport 40(1): 71-88.

Singh G (2003) Multiculturalism in contemporary Britain: Reflections on the 'Leicester Model'. International Journal of Multicultural Societies 5(1): 40-51.

Singh G (2005) A city of surprises: Urban multiculturalism and the Leicester Model. In: Ali N, Khalra V, Sayid S (eds) A Post Colonial People: South Asians in Britain. London: Hurst, 291-304.

Taylor I, Evans K and Fraser P (1996) Global Change, Local Feeling and Everyday Life in the North of England: A Tale of Two Cities, A Study in Manchester and Sheffield. London: Routledge.

Westwood S (1990) Racism, black masculinity and the politics of space. In: Hearn J, Morgan D (eds) Men, Masculinities and Social Theory. London: Unwin and Hyman, $55-71$.

44 International Review for the Sociology of Sport 46(1)

Westwood S (1991) Red star over Leicester: Racism, the politics of identity and black youth in Britain. In: Werbner P, Anwar M (eds) Black and Ethnic Leadership in Britain. London: Routledge, 146-169.

Williams J (1984) On the football front, SNCCFR, University of Leicester.

Williams J (1992) Lick my boots: Racism in English football, SNCCFR, University of Leicester.

Williams J (1994) Rangers is a black club: Race, identity and local football in England. In: Guilianotti R, Williams J (eds) Game Without Frontiers: Football Identity and Modernity. Aldershot: Arena.

Williams J (1999) English football and national identity, SNCCFR, University of Leicester.

Williams J et al. (2001a) FA Premier League National Fan Survey, SNCCFR, University of Leicester.

Williams J et al. (2001b) Football League fan survey: a national survey of Football League club fans, SNCCFR, University of Leicester.

Williams R (1977) Marxism and Literature. Oxford: Berg. 
Woodward K (2004) Rumbles in the jungle: Racialisation and the performance of masculinity. Leisure Studies 23(1): 5-17. 